Artikel Penelitian

\title{
Ekstraksi Minyak Atsiri dari Bunga Mawar (Rosa hybrda L.) dengan Metode Solvent-Free Microwave Extraction
}

\author{
Yuyun Yuniati ${ }^{1}$, Saras Nurani Putri², Pradipta Risang Ratna Sambawa², Donny Satria Bhuana ${ }^{2}$, Mahfud Mahfud²* \\ 1Program Studi Kimia, Fakultas Sains dan Teknologi, Universitas Ma Chung, Malang, Indonesia, 65151 \\ 2Departemen Teknik Kimia, Fakultas Teknologi Industri, Institut Teknologi Sepuluh Nopember Surabaya, Indonesia, 60117
}

\section{INFO ARTIKEL}

\section{Riwayat Artikel}

Diterima 2 Februari 2021

Direvisi 24 Agustus 2021

Tersedia online 14 Oktober 2021

\footnotetext{
* Penulis korespondensi:

mahfud@chem-eng.its.ac.id
}

\section{ABSTRAK}

To date, essential oils still play an important role in various aspects of human life. Flowers are essential oil-producing plants that still need to be further explored, of which rose petals (Rosa hybrda L.) are an option for types of flowers that have the potential to produce economical essential oils. In this study, solvent-free microwave extraction (SFME) was used as an essential oil extraction method, which is considered safe because it does not use heat energy and chemical solvents which can be considered to trigger a decrease in the quality of the oil extract. The optimum microwave power in this study is 560 Watt with a yield of $0.0124 \%$. The difference in the value of the feed intake ratio to the volume of the distiller (F/D) influences yield, where the F/D value of $0.15 \mathrm{~g} / \mathrm{mL}$ gives the highest yield value of $0.0145 \%$. The result of the Gas Chromatography Mass Spectrometry (GCMS) analysis shows rose flower essential oil extract provided a profile of 12 compounds, of which three dominant compounds are $\beta$-phenylethyl acetate, 2isopropyl-5-methyl-9-methylene-bicyclo-1-decene, and nonadecane.

Keywords: Extraction, rose flower petals, solvent-free microwave extraction (SFME), essential oils

Hingga saat ini, minyak atsiri masih memegang peranan penting untuk berbagai aspek kehidupan manusia. Bunga-bungaan merupakan tanaman penghasil minyak atsiri yang masih perlu dieksplorasi lebih lanjut, yang mana mahkota bunga mawar (Rosa hybrda L.) adalah satu opsi jenis bunga yang berpotensi sebagai penghasil minyak atsiri bernilai ekonomis. Pada penelitian ini digunakan solventfree microwave extraction (SFME) sebagai metode ekstraksi minyak atsiri yang dinilai aman karena tidak menggunakan energi panas dan bahan pelarut kimia yang dapat dianggap memicu penurunan kualitas ekstrak minyak. Daya microwave optimum pada penelitian ini adalah 560 Watt dengan perolehan yield sebesar $0,0124 \%$. Perbedaan nilai rasio feed masuk terhadap volume distiler (F/D) memberikan pengaruh terhadap hasil rendemen, yang mana nilai F/D 0,15 g/mL memberikan nilai rendemen tertinggi sebesar 0,0145\%. Hasil analisis Gas Chromatography Mass Spectrometry (GCMS) menunjukkan bahwa ekstrak minyak atsiri bunga mawar memberikan profil 12 senyawa dengan tiga senyawa dominan yaitu $\beta$-phenylethyl acetate, 2-isopropyl-5-methyl-9-methylene-bicyclo-1decene, dan nonadecane.

Kata kunci: Ekstraksi, mahkota bunga mawar, solvent-free microwave extraction (SFME), minyak atsiri 


\section{Pendahuluan}

Minyak atsiri adalah produk zat kimia alam mudah menguap yang berasal dari organ suatu tumbuhan yang memberikan sifat aromatik secara terkonsentrasi. Hingga saat ini, minyak atsiri masih memiliki peran penting bagi masyarakat, termasuk untuk bahan kosmetik, pangan, farmasi, terapi hingga aspek spiritual [1]. Minyak atsiri juga telah terbukti memiliki khasiat sebagai agen antibakteri dan antibiotik yang secara praktis memberikan pengaruh untuk pengobatan beberapa penyakit seperti kardiovaskular, kanker, dan kelainan saraf. Oleh karena itu, berbagai industri dan peneliti terus mengupayakan pengembangan ekstraksi minyak atsiri dari berbagai produk alam yang ada di berbagai belahan dunia [2].

Indonesia menjadi salah satu negara yang memiliki keberagaman varietas tumbuhan tropis yang menyediakan kandungan minyak atsiri didalamnya, sehubungan dengan letak astronomis negara yang dilalui oleh garis khatulistiwa [3]. Tercatat sudah lebih dari 80 jenis minyak atsiri asal tumbuhan Indonesia yang berhasil diperdagangkan, dan kini angka penjualannya semakin meningkat. Akan tetapi, pengambilan minyak atsiri dari bunga-bungaan masih belum dimanfaatkan lebih banyak sehingga perlu dieksplorasi lebih lanjut. Salah satu jenis bunga yang memiliki potensi sebagai penghasil minyak atsiri bernilai ekonomis adalah tanaman hias bunga mawar (Rosa hybrda L.) [4].

Berkaitan dengan perolehan zat ekstrak alami suatu tumbuhan, saat ini terdapat beberapa metode ekstraksi yang sudah dilakukan yaitu maserasi [5], distilasi [6, 7] dan sonikasi [8]. Akan tetapi, adanya penggunaan energi panas dan pelarut kimia sebagai media ekstraksi dianggap kurang baik dalam perolehan produk akhir, dimana kandungan senyawa pada minyak atsiri memiliki sifat volatil, sensitif terhadap reaksi degradasi, dan rentan tercampur dengan residu bahan pelarut beracun [9]. Oleh karena itu, diperlukan metode ekstraksi yang aman dalam menghasilkan ekstrak minyak atsiri yang berkualitas. Metode solvent-free microwave extraction (SFME) diperkenalkan sebagai metode ekstraksi lanjutan dari metode microwave assisted extraction (MAE) dalam mengekstraksi produk alami tanpa penambahan pelarut berbahaya dan energi tinggi dengan sedikit modifikasi metode tambahan [10, 11].

Penelitian awal terkait metode ekstraksi SFME pada bunga mawar sangat diperlukan untuk mengetahui kondisi optimum ekstraksi untuk mendapatkan zat ekstrak dengan persentase yield setinggi-tingginya [11,12]. Selain itu, penelitian ini juga diperlukan untuk mengetahui kandungan senyawa yang ada pada minyak atsiri yang berhasil diekstrak dengan metode green chemistry. Diharapkan studi ini dapat memberikan informasi mengenai proses pengambilan minyak mawar yang efektif dan efisien, serta memberikan informasi untuk pengkajian lanjutan terhadap minyak atsiri bunga mawar.

\section{Bahan dan Metode}

\subsection{Bahan}

Pada penelitian ini digunakan mahkota bunga mawar yang diperoleh dari wilayah Bandungan (Semarang, Jawa Tengah). Pelarut $n$-heksana (99\% Pro Analysis, Merck) digunakan untuk kebutuhan partisi.

\subsection{Ekstraksi Minyak Atsiri}

Optimasi ekstraksi dilakukan dengan menyiapkan tiga variabel yang dibedakan atas rasio feed masuk terhadap volume distiler (F/D), yaitu sebesar 0,$15 ; 0,25 ;$ dan $0,40 \mathrm{~g} / \mathrm{mL}$. Ekstraksi dilakukan dengan pengaturan daya microwave sebesar 560 Watt dan diproses selama 60 menit. Hasil tampungan campuran ekstrak minyak atsiri bunga mawar dan air kemudian dipartisi dengan $n$-heksana, sehingga diperoleh komponen minyak atsiri. Setelah proses ekstrasi selesai, pada campuran minyak dan air pada clavenger ditambahkan $10 \mathrm{~mL} n$-heksana untuk mengikat minyak yang tercampur di air. Selanjutnya $n$-heksana dipisahkan dengan cara diuapkan pada waterbath pada suhu ruang. Ekstrak minyak atsiri kemudian dihitung nilai persentase yield terhadap berat bahan baku awalnya. Kandungan senyawa kimia dalam ekstrak minyak atsiri dianalisis dengan Gas Chromatography Mass Spectrometry (GCMS).

\section{Hasil dan Pembahasan}

\subsection{Ekstraksi Mlnyak Atsiri Bunga Mawar}

Penggunaan metode SFME didesain untuk skala laboratorium dengan menempatkan bahan baku dalam reaktor yang diatur dalam gelombang mikro tanpa menggunakan bahan pelarut kimia. Bagian mahkota bunga mawar digunakan sebagai bahan baku utama ekstraksi minyak atsiri karena dinilai memiliki aroma yang lebih harum dibandingkan dengan bagian bunga lain. Selama proses ekstraksi, terjadi pembengkakan sel tumbuhan yang menyebabkan pecahnya kelenjar sehingga minyak atsiri dapat dikeluarkan dari matriks tanaman dalam bentuk uap. Penguapan diatur pada suhu sedang dengan tujuan untuk mencegah adanya degradasi atau kerusakan pada komponen yang ada pada minyak atsiri. Proses pendinginan di luar reaktor microwave digunakan untuk mengkondensasikan hasil destilasi sehingga dapat diperoleh zat ekstrak cair bunga mawar yang diinginkan [10]. 
Campuran zat ekstrak dengan air perlu dipisahkan lebih lanjut. Senyawa $n$-heksana yang memiliki karakteristik sebagai zat pelarut organik yang mampu mengikat bagian minyak atsiri yang bersifat non polar sehingga diperoleh zat ekstrak yang lebih murni [13]. Hal ini diperlukan untuk menjerap minyak atsiri yang dihasilkan melalui proses ekstraksi. Penggambaran metode ekstraksi minyak atsiri bunga mawar dengan metode SFME dapat diamati pada Gambar 1.
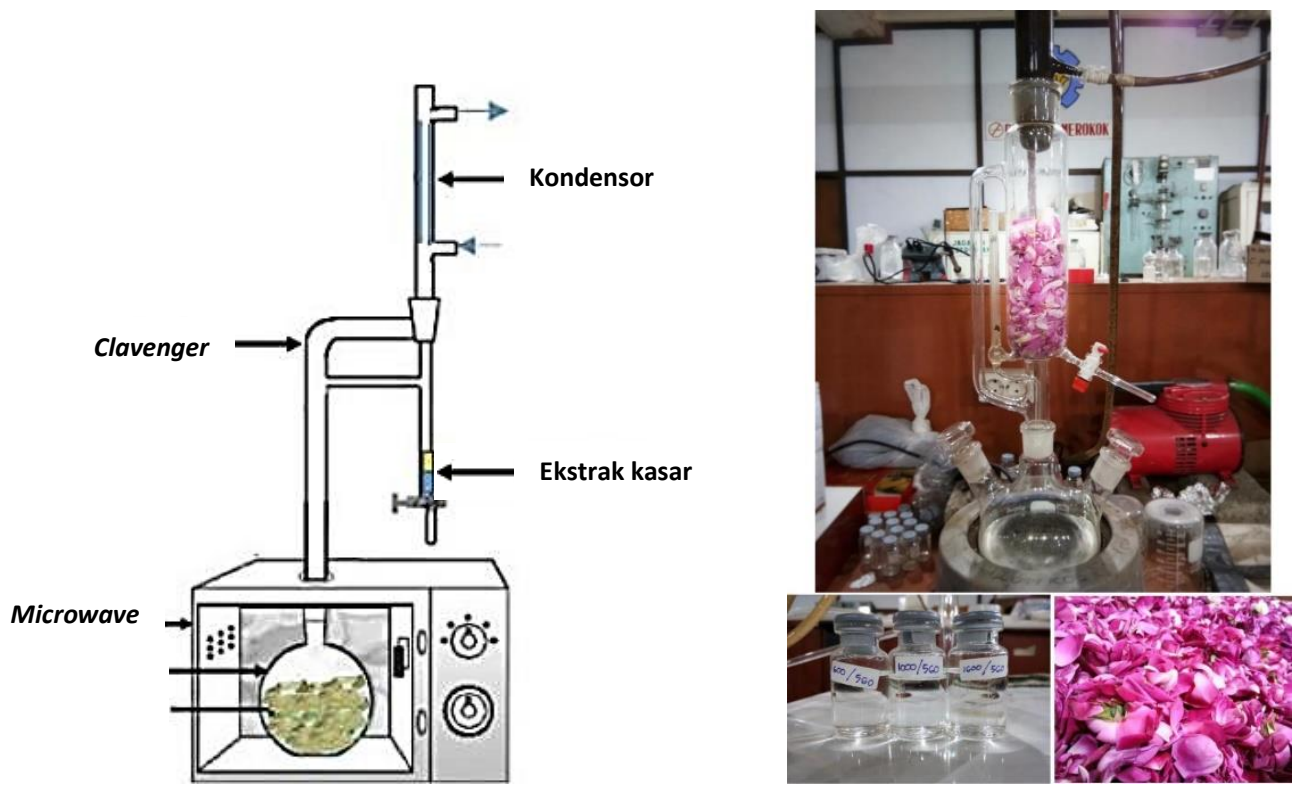

Gambar 1. Desain ekstraksi minyak atsiri bunga mawar dengan metode SFME

\subsection{Pengaruh Daya Microwave}

Daya dalam proses ekstraksi memiliki pengaruh terhadap yield minyak atsiri. Dalam proses ekstraksi menggunakan microwave, daya memiliki andil dalam mengontrol besarnya energi yang akan diterima oleh bahan tanaman untuk diubah menjadi energi panas. Energi panas ini yang membantu proses keluarnya minyak atsiri dari bahan yang akan diekstrak.

Tabel 1. Pengaruh Daya Microwave terhadap Yield (\%)

\begin{tabular}{cc}
\hline Daya Microwave (Watt) & Yield (\%) \\
\hline 280 & 0,008 \\
420 & 0,0093 \\
560 & 0,0124 \\
700 & 0,0105 \\
\hline
\end{tabular}

Penggunaan daya microwave yang tinggi akan mempercepat pemanasan terhadap bahan yang diekstrak seiring dengan semakin tinggi pula suhu pemanasan terhadap bahan yang diekstraksi. Pada penelitian ini, pengaruh daya microwave terhadap persentase yield ekstrak minyak atsiri dapat dilihat pada Tabel 1. Yield tertinggi diperoleh pada penggunaan daya 560 Watt dengan nilai sebesar $0,0124 \%$. Namun, jika daya ditingkatkan lagi (700 Watt) maka perolehan yield akan menurun $(0,0105 \%)$. Hal ini disebabkan karena pada daya dan suhu tinggi dapat merusak jaringan minyak atsiri. Adanya kenaikan suhu menyebabkan proses penguapan terjadi sangat cepat dan menyebabkan terjadinya degradasi terhadap bahan yang diesktrak [14].

\subsection{Pengaruh Nilai Rasio terhadap Yield Ekstraksi}

Berdasarkan Tabel 2 diketahui bahwa adanya perbedaan nilai rasio F/D bahan baku memberikan pengaruh terhadap hasil persentase yield ekstrak minyak atsiri. Pada rasio F/D sebesar $0,15 \mathrm{~g} / \mathrm{mL}$ diperoleh nilai yield dan akumulasi recovery ekstrak minyak yang paling tinggi, yakni 0,0145 dan $11,34 \%$. Nilai akumulasi recovery optimum dari variabel ini diperoleh dari faktor kepadatan bahan yang mana memungkinkan perpindahan panas pada bahan dalam distiller menjadi lebih optimum. Hasil perolehan yield minyak atsiri bunga mawar dengan metode SFME ternyata lebih tinggi dibandingkan nilai rendemen absolut bunga mawar $(0,076 \%)$ yang diperoleh dari teknik enfleurasi (selang waktu defleurasi 12 jam) sebagai metode ekstraksi [15]. 
Tabel 2. Pengaruh Nilai Rasio terhadap Yield (\%)

\begin{tabular}{cc}
\hline Rasio F/D $(\mathrm{g} / \mathrm{mL})$ & Yield (\%) \\
\hline 0,15 & 0,0145 \\
0,25 & 0,0143 \\
0,4 & 0,0116 \\
\hline
\end{tabular}

Persentase yield minyak mawar semakin menurun seiring bertambahnya massa bahan yang diekstrak. Hal ini disebabkan oleh pengaruh luas permukaan bahan pada pemanasan. Massa bahan yang bertambah menyebabkan bahan dalam labu semakin padat sehingga tidak ada ruang bagi panas. Akibatnya, sebagian permukaan bahan tidak terkena panas secara optimal. Semakin berkurang massa bahan, maka semakin berongga kepadatan massa bahan, panas dapat masuk melalui celah celah di antara bahan, luas permukaan pemanasan menjadi meningkat. Hal ini yang menyebabkan yield meningkat seiring turunnya massa bahan yang diekstrak [16].

\subsection{Analisis GCMS Ekstrak Minyak Atsiri Bunga Mawar}

Untuk mengetahui komponen-komponen yang terkandung dalam minyak atsiri bunga mawar digunakan GCMS sebagai metode analisis. Profil GCMS minyak atsiri bunga mawar ditunjukkan pada Gambar 2. Profil GCMS memberi informasi bahwa ekstrak minyak atsiri bunga mawar mengandung tiga senyawa utama yang memiliki persentase area di atas $10 \%$, yakni $\beta$-phenylethyl acetate (17,26\%), 2-isopropyl-5-methyl-9-methylene-bicyclo-1-decene (13,67\%), dan nonadecane $(17,61 \%)$ (Tabel 3). Ketiga senyawa dominan dan sembilan senyawa lainnya merupakan senyawa kimia yang ada pada bunga mawar [17].

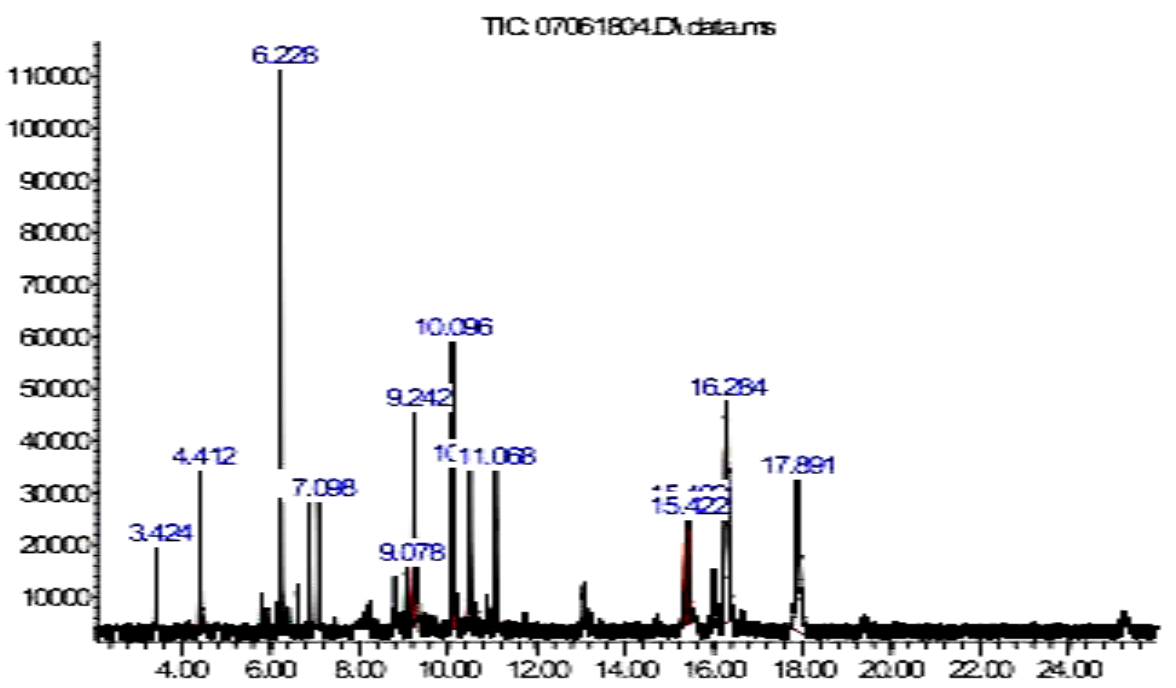

Gambar 2. Profil analisis GCMS pada ekstrak minyak atsiri bunga mawar

Tabel 3. Komponen Senyawa Volatil pada Ekstrak Minyak Atsiri Bunga Mawar

\begin{tabular}{|c|c|}
\hline Komponen & Area (\%) \\
\hline Phenylethyl alcohol & 5,06 \\
\hline$\beta$-Phenylethyl acetate & 17,26 \\
\hline Theaspirane & 4,20 \\
\hline (E,E)-2-methyl-6-oxohepta-2,4-dienal & 3,33 \\
\hline N,N-Dimethylmethanesulfonamide & 3,25 \\
\hline$\beta$-dihydroionol & 6,37 \\
\hline 2-Isopropyl-5-methyl-9-methylene-bicyclo-1-decene & 13,67 \\
\hline a-Fernesene & 8,75 \\
\hline$\delta$-Cadinene & 7,86 \\
\hline$y$-cadinene & 8,32 \\
\hline Eugenol & 4,32 \\
\hline Nonadecane & 17,61 \\
\hline
\end{tabular}




\section{Kesimpulan}

Berdasarkan hasil penelitian yang telah dilakukan maka dapat disimpulkan bahwa daya microwave memiliki pengaruh terhadap perolehan persentase yield. Daya microwave optimum diperoleh pada 560 Watt dengan nilai yield sebesar $0,0124 \%$. Selain itu, juga diketahui bahwa rasio F/D optimum untuk proses ekstraksi bunga mawar dengan SFME adalah $0,15 \mathrm{~g} / \mathrm{mL}$ dengan perolehan yield minyak atsiri sebesar $0,0145 \%$. Berdasarkan analisis GCMS, ekstrak minyak atsiri bunga mawar mengandung tiga senyawa dominan, yakni $\beta$-phenylethyl acetate, 2 isopropyl-5-methyl-9-methylene-bicyclo-1-decene, dan nonadecane.

\section{Daftar Pustaka}

[1] K. P. Svoboda \& S. G. Deans, "Biological Activities of Essential Oils from Selected Aromatic Plants," Acta Horticulturae, vol. 390, pp. 203-209, 1995.

[2] M. Inoue, S. Hayashi, \& L. E. Craker, "Role of Medicinal and Aromatic Plants: Past, Present, and Future. In Pharmacognosy-Medicinal Plants," in Pharmacognosy-Medicinal Plants, London: IntechOpen, 2019, pp. 13-26.

[3] C. Kusmana \& A. Hikmat, "Keanekaragaman Hayati Flora di Indonesia," Jurnal Pengelolaan Sumberdaya Alam dan Lingkungan, vol. 5, no. 2, pp. 187-198, 2015.

[4] T. S. Julianto, Minyak Atsiri Bunga Indonesia 1st Ed. Sleman: Deepublish Publisher, 2016.

[5] A. Damayanti, \& A. Fitriana, "Pemungutan Minyak Atsiri Mawar (Rose Oil) dengan Metode Maserasi," Jurnal Bahan Alam Terbarukan, vol. 1, no. 2, pp. 1-8, 2012.

[6] M. Mahfud, A. C. K. Fitri, L. Qadariyah, \& P. Prihatini, "Distillation Assisted by Microwave for Extracting Essential Oil from Java Cananga Flowers," Modern Applied Science, vol. 9, no. 7, p. 199-205, 2015.

[7] L. K. Dewi, D. L. Friatnasary, W. Herawati, V. Nurhadianty, \& C. Cahyani, "Studi Perbandingan Metode Isolasi Ekstraksi Pelarut dan Destilasi Uap Minyak Atsiri Kemangi terhadap Komposisi Senyawa Aktif," Jurnal Rekayasa Bahan Alam dan Energi Berkelanjutan, vol. 2, no. 1, pp. 13-19, 2018.

[8] A. Handaratri \& Y. Yuniati, "Kajian Ekstraksi Antosianin dari Buah Murbei dengan Metode Sonikasi dan Microwave," Reka Buana: Jurnal IImiah Teknik Sipil dan Teknik Kimia, vol. 4, no. 1, pp. 63-67, 2019.

[9] B. Bayramoglu, S. Sahin, \& G. Sumnu, "Solvent-Free Microwave Extraction of Essential Oil from Oregano," Journal Food Engineering, vol. 88, no. 4, pp. 535-540, 2008.

[10] M. E. Lucchesi, F. Chemat, \& J. Smadja, "Solvent-Free Microwave Extraction: An Innovative Tool for Rapid Extraction of Essential Oil frof om Aromatic Herbs and Spices," Journal of Microwave Power and Electromagnetic Energy, vol. 39, no. 3-4, pp. 135-139, 2004.

[11] D. K. Y. Putri, I. E. P. Dewi, H. S. Kusuma, \& M. Mahfud, "Extraction of an Essential Oil from Fresh Cananga Flowers (Cananga odorata) using Solvent-Free Microwave Method," Journal of Chemical Technology and Metallurgy, vol. 54, no. 4, pp. 793-802, 2019.

[12] Y. Yuniati, P. E. Elim, R. Alfanaar, H. S. Kusuma, \& M. Mahfud, "Extraction of Anthocyanin Pigment from Hibiscus sabdariffa L. by Ultrasonic-Assisted Extraction," in IOP Conference Series: Materials Science and Engineering, The $2^{\text {nd }}$ International Conference on Advanced Engineering and Technology 2020, vol. 1010, no 012032, 2020.

[13] F. Chemat, M. A. Vian, H. K. Ravi, B. Khadhraoui, S. Hilali, S. Perino, \& A.-S. F. Tixier, "Review of Alternative Solvents for Green Extraction of Food and Natural Products: Panorama, Principles, Applications and Prospects," Molecules, vol. 24, no. 3007, 2019.

[14] Z. Hu, M.Cai \& H. Liang, "Desirability Function Approach for the Optimization of Microwave-assisted Extraction of Saikosaponins from Radix Bupleuri," Separation and Purification Technology, vol. 61, no. 3, pp. 266-275, 2008.

[15] Yulianingsih, D. Amiarsi, \& S. S. Diharjo, "Teknik Enfleurasi dalam Proses Pembuatan Minyak Mawar," Jurnal Hortikultura, vol. 17, no. 4, pp. 393-398, 2007.

[16] E. T. Akhihiero, B. V. Ayodele, \& G. E. Akpojotor, "Effect of Particle Size and Temperature Variation on the Yield of Essential Oil From Lemon Grass using Steam Distillation," African Journal of Physics, vol. 6, pp. 105-112, 2013.

[17] K. J. Naquvi, S. H. Ansari, M. Ali, \& A. K. Najmi, "Volatile Oil Composition of Rosa damascena Mill. (Rosaceae)," Journal of Pharmacognosy and Phytochemistry, vol. 2, no. 5, pp. 130-134, 2014. 